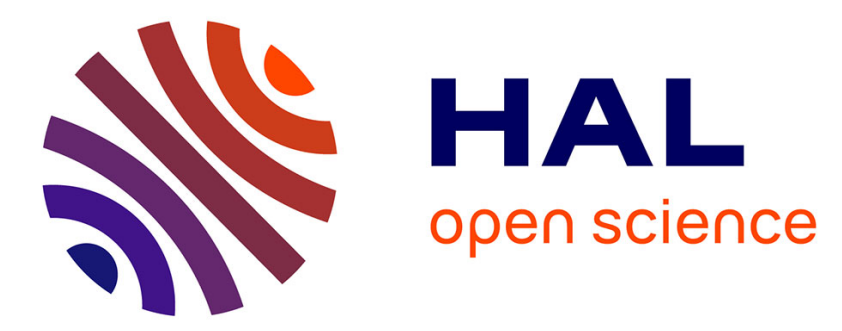

\title{
A Framework to Evaluate Semiotic Interoperability for Information Sharing
}

Shixiong Liu, Weizi Li

\section{To cite this version:}

Shixiong Liu, Weizi Li. A Framework to Evaluate Semiotic Interoperability for Information Sharing. 18th International Conference on Informatics and Semiotics in Organisations (ICISO), Jul 2018, Reading, United Kingdom. pp.83-93, 10.1007/978-3-319-94541-5_9 . hal-01920724

\section{HAL Id: hal-01920724 \\ https://hal.inria.fr/hal-01920724}

Submitted on 13 Nov 2018

HAL is a multi-disciplinary open access archive for the deposit and dissemination of scientific research documents, whether they are published or not. The documents may come from teaching and research institutions in France or abroad, or from public or private research centers.
L'archive ouverte pluridisciplinaire HAL, est destinée au dépôt et à la diffusion de documents scientifiques de niveau recherche, publiés ou non, émanant des établissements d'enseignement et de recherche français ou étrangers, des laboratoires publics ou privés. 


\title{
A Framework to Evaluate Semiotic Interoperability for Information Sharing
}

\author{
Shixiong Liu and Weizi Li \\ Informatics Research Centre, University of Reading, Reading, RG6 6UD, UK \\ \{L.s.liu,Weizi.li\} @henley.ac.uk
}

\begin{abstract}
Interoperability is the ability of entities in organisation to work together that covers aspects ranging from the technical to the business level. Over the last decades, the interoperability concept and its context have been changing rapidly. It expands from the largely IT-focused area to business-focused area. The evaluation of interoperability is a rising concern in various research domains. There is increasing number of researchers that have been started concentrating on not just digital aspects, but also business related, human related, and social environment related aspects. Our previous investigation reveals in that interoperability issues from those perspectives are becoming a rising concern. When we study information sharing and business collaboration within organisations, the business activities and operations in organisation, which directly affect business performance, are driven by business processes. Therefore, the interoperability between business processes is the key to information sharing assurance. This paper proposes a framework from a new perspective - semiotics perspective, for enhancing interoperability evaluation. The framework derives from a feasibility study that investigates interoperability barriers in organisation. The framework offers the capabilities of analysing, measuring, and assessing the interoperability between business processes.
\end{abstract}

Keywords: Interoperability Evaluation, Semiotic Interoperability, Information Sharing, Business Process.

\section{Introduction}

In the current industrial and economic context, market demand and technological evolution are changing sharply. Organisations seek to become more agile, responsive and competitive. Enterprises tend to maximise their Information Technology investment in order to support information sharing among not only digital systems, but also business processes (Clabby, 2003). Panian (2006) summarises two business drivers: 1) the need to consolidate and globalise, which indicates that many leftover mission-critical systems caused by mergers and acquisitions are requiring a better interoperability between them in order to enhance information utilisation; and 2) the search for increased productivity, indicates that collaboration of business processes can aid organisations to increase productivity and to reduce costs. The successful collaboration provides instant operations for organisations, which lead to optimise decision-making processes (Chen, 
Doumeingts, \& Vernadat, 2008; EN/ISO I9439, 2003). Successful information sharing also helps stakeholders to manage in responding to the changes (Kaye, 2003), and improve organisation's agility by providing the flexibility to quickly adapt information systems in order to accommodate growth and meet arisen business challenges. In order to study the effectiveness of the information sharing between digital systems and between business processes in responding to the changes of market demand and technological innovation, the concept of interoperability, which was originally used for evaluating connection of technical devices and integration of ICT systems, is becoming a widely accepted tool for assessing not just the technical integration, but also collaboration in business in the last decade (Liu et al., 2013).

Interoperability is the ability of entities in organisation to work together that covers aspects ranging from the technical to the business level. Over the last decades, the interoperability concept and its context have been changing rapidly. It expands from the largely IT-focused area to business-focused area. The evaluation of interoperability is a rising concern in various research domains. There is increasing number of researchers that have been started concentrating on not just digital aspects, but also business related, human related, and social environment related aspects. Our previous investigation reveals in that interoperability issues from those perspectives are becoming a rising concern. When we study information sharing and business collaboration within organisations, the business activities and operations in organisation, which directly affect business performance, are driven by business processes. Therefore, the interoperability between business processes is the key to information sharing assurance. This paper proposes a framework from a new perspective - semiotics perspective, for enhancing interoperability evaluation. The framework derives from a feasibility study that investigates interoperability barriers in organisation. The framework offers the capabilities of analysing, measuring, and assessing the interoperability between business processes. The paper starts with a recap of previous study on evaluation of semiotic interoperability, and then conducts a feasibility study that adopts organisational morphology to investigate barriers at three layers (i.e. Informal, Formal, and Technical). The identified barriers and its corresponding solutions are consolidated to form a framework - Semiotic Interoperability Evaluation Framework, which is proposed with discussion in the end of this paper.

\section{Background}

\subsection{Semiotic Interoperability Definition}

In our previous work (Liu, 2015; $\mathrm{Li}, 2013$ ), the concept of semiotic interoperability is defined based on the semiotic framework from organisational semiotics. As introduced the semiotic framework provides a sound theoretical foundation for understanding of the nature of the sign-based communication, and a holistic view about signs, information, systems and organisations (Stamper, 1973; Liu, 2000). The semiotic interoperability allows information systems to work together through communication, and also 
enables collaboration of business processes through understanding of intention and social consequence. Fig 1 describes the concept of semiotic interoperability and its functional context at six constituting levels.

Physical interoperability enables seamless communication between senders and receiver handling the physical tokens transmitted via a route at the destination without loss of physical properties. Interoperability at Empiric level is achieved when the receiver can reconstitute the same sequence of symbols that were sent by the sender, irrespective of any problems at the physical level. Interoperability at Syntactic level is achieved when the expression of information, or language, or formula can be recognised by different information systems. The data structures and format of file and message have to be readable to both ends of communication. Semantic interoperability can be achieved to give the same meaning to exchanged information between information systems, and it requires a conceptual model which describes what information is exchanged in terms of concepts, properties, and relationships between these concepts. More specifically, the semantic interoperability not only entails the data to be universally accessible and reusable, but also address the lack of common understanding caused by the use of different semantic representations, different purposes, different contexts, and different syntax-dependent approaches. Interoperability at the pragmatic level ensures that business processes supported by the information systems in individual contexts can be aggregated to achieve the overall intended purpose. It enables the alignment of business workflows, alignment of processes, and alignment of rules. Besides, the pragmatic interoperability also aligns social aspects such as culture, norms, environment, and actor's behaviour patterns in order to solve conflicts of cohesiveness. Interoperability at Social level ensures the intention or purpose of the sender has led to a social consequence to the receiver, and the social consequence can be social commitment, obligation, and norms. The social interoperability also ensures that those social consequences support the business strategy, vision, objectives, and the business environment. There are a few sub-areas under the topic of social interoperability such as alignment in traditions, alignment in policies, alignment in culture, alignment in ethics, alignment in management style, and alignment in environment (Barbarito et al., 2012; Boonstra, Broekhuis, Offenbeek, \& Wortmann, 2011; Gregory, Dixon, \& Ham, 2012; S. Liu, Li, \& Liu, 2014; Saag et al., 2012), those sub-areas cannot represent all the concerns and issues that social interoperability deals with, because the topic is still under investigation and development. 


\begin{tabular}{|c|c|c|}
\hline & Definition & $\begin{array}{l}\text { Functional Context \& Relevant } \\
\text { Methods }\end{array}$ \\
\hline $\begin{array}{l}\text { Social } \\
\text { level }\end{array}$ & $\begin{array}{l}\text { The resultant interoperable digital systems should } \\
\text { be coherent with the social commitment, obligation } \\
\text { and norms in the organisation and support } \\
\text { organisation's strategy, vision and objectives }\end{array}$ & $\begin{array}{l}\text { Alignment in traditions } \\
\text { Alignment in policies } \\
\text { Alignment in culture } \\
\text { Alignment in ethics } \\
\text { Alignment in management style } \\
\text { Alignment in environment etc. } \\
\text { Process reengineering }\end{array}$ \\
\hline $\begin{array}{l}\text { Pragmatic } \\
\text { level }\end{array}$ & $\begin{array}{l}\text { Business processes supported by the digital } \\
\text { systems in their individual contexts can be } \\
\text { aggregated to achieve the overall intended purpose }\end{array}$ & $\begin{array}{l}\text { Process alignment } \\
\text { Rules modelling } \\
\text { Knowledge sharing \& knowledge } \\
\text { repositories } \\
\text { Business strategy alignment etc. }\end{array}$ \\
\hline $\begin{array}{l}\text { Semantic } \\
\text { level }\end{array}$ & $\begin{array}{l}\text { Ability of interpreting and converting information } \\
\text { into equivalent meaning to allow information } \\
\text { sharing between digital systems }\end{array}$ & $\begin{array}{l}\text { Semantic data representation } \\
\text { Data standardisation } \\
\text { Schema matching } \\
\text { Ontology mapping } \\
\text { Semantic matching etc. }\end{array}$ \\
\hline $\begin{array}{l}\text { Syntactic } \\
\text { level }\end{array}$ & $\begin{array}{l}\text { Consistence between data formats, structures and } \\
\text { programming languages supporting data } \\
\text { transmission }\end{array}$ & $\begin{array}{l}\text { Data warehousing } \\
\text { Data integration e.g. ETL (Extract, } \\
\text { Transform and Load), EDI } \\
\text { (Electronic data interchange) }\end{array}$ \\
\hline $\begin{array}{l}\text { Empiric } \\
\text { level }\end{array}$ & $\begin{array}{l}\text { Compatibility between channels and protocols } \\
\text { supporting data transmission }\end{array}$ & $\begin{array}{l}\text { Communication systems } \\
\text { Messaging systems }\end{array}$ \\
\hline $\begin{array}{l}\text { Physical } \\
\text { level }\end{array}$ & $\begin{array}{l}\text { Connectivity between networks and hardware and } \\
\text { devices }\end{array}$ & $\begin{array}{l}\text { Infrastructure standardisation } \\
\text { EA (technology layer) and ITIL } \\
\text { (Information Technology } \\
\text { Infrastructure Library) }\end{array}$ \\
\hline
\end{tabular}

Fig. 1. Semiotic Interoperability

\subsection{Evaluating Interoperability between Business Processes}

The focus of this paper is the upper two levels of the semiotic interoperability: pragmatic and social levels. In our previous studies, a review of all existing interoperability evaluation frameworks points out that most of current works have tackled the interoperability issues at the semantic, syntactic, empiric and physical levels (Liu, 2014). But very limited amount of works is concentrating on evaluating interoperability at pragmatic and social levels. According to the definition of semiotic interoperability, the pragmatic interoperability is to ensure that business processes supported by the information systems in individual contexts can be aggregated to achieve the overall intended purpose. To evaluate the interoperability between business processes, this thesis deals with the issue from the organisational morphology perspective. As discussed in the first previous sections in this chapter, organisation can be seen as an information system, because information is created, stored, and processed for communication, coordination and achieving the organisational objectives (Liu et al., 2002). From an organisational perspective, information systems are defined by the cultural and legal norms that regulate people's behaviour (Gazendam and Liu, 2005). Thus, the definition of organisation is extended to a wider sense such that, a group of people, a society, a culture, do not only share language, customs, and habits, but also participate in the social construction 
of their own rules. In summary, the organisation is regarded as an informal information system where meanings are established, intentions are understood, beliefs are formed, commitments are made, and responsibilities are negotiated through the decision of physical actions. The organisation morphology categorises those meanings, intentions, beliefs, commitments, and responsibilities into three layers: the formal, the informal, and the technical. Business processes, at the formal layer, plays dominant role that drives business activity and operation, which directly affects business performance. However, the business process cannot be treated in isolation to aspects at other two layers: the informal and the technical. Because the studies in information system have never treated the information system as a set of separate components but considered it as a whole. Thus, the business process also requires supports from both technical and informal layers. According to the definitions given by Li (2010) and Zutshi et al. (2012), business process is a set of activities that occur in a coordinated manner pursuing one common goal. By looking at the entire information system, the activities are dynamic in nature but consider static aspects as well. The dynamic aspects include culture, norms, different behaviour patterns; and the static aspects include technical system capacity, data structure, data transmission, connection etc. Therefore, to evaluate the interoperability between business processes is to evaluate the interoperability at the formal, the informal, and the technical layers. Table 1 describes the key aspects at each layer.

Table 1. Three layers for evaluating interoperability between business processes.

\begin{tabular}{ll}
\hline Layer & Description \\
\hline Informal & Community, social norm, people, policy, culture, eth- \\
& ics, environment, alliances etc. \\
Formal & Organisational strategy/vision, business governance, \\
& domain analysis, organisational roles, functional pro- \\
& file, rules, procedures, management etc. \\
Technical & Data semantics, information infrastructure, infor- \\
& mation model, schema, script, interface, platform, de- \\
& ployment model, resources, products etc. \\
\hline
\end{tabular}

The informal layer contains aspects such as community, social norm, policy, and culture. Those aspects can be expanded to be different behaviour patterns of both organisations and individuals. The interoperability at this layer is to align the different aspects in order to solve conflicts of cohesiveness. In the formal layer, business process plays dominant role that specifies on how functions should be carried out and how tasks should be performed. The interoperability at this layer is to align procedures and rules in order to achieve higher efficiency. It defines business goals, and models business processes, also brings the collaboration of administrations that aims to exchange information and have different internal structures and processes. The technical layer mostly refers to the technical computer systems and the implementation of their services, integration, and functions. The interoperability at this layer is to align technical functions 
and interfaces ensuring that the implementation has been done properly in order to achieve higher system productivity.

The organisational morphology theory is applied to evaluate interoperability between business processes from three layers: the formal, the informal, and the technical. The three levels are the foundation for developing the framework - Semiotic Interoperability Evaluation Framework (SIEF). Before proposing the SIEF, it is necessary to investigate the feasibility. To conduct a feasibility study, several industrial cases for interoperability evaluation are investigated. The findings of the feasibility study identify concerns and barriers at the three layers when considering interoperability evaluation between business processes and those concerns and barriers will be later transformed into metrics contributing to the SIEF.

\section{Findings of Feasibility Study}

The feasibility study is mainly conducted through interviews and surveys in a healthcare software company and one of the hospitals in China where the company provides solutions for. The company currently runs an integration project, which aims to enable information sharing among systems such as Radiology Information Systems (RIS), Electronic Health Record (EHR), and Picture Archiving and Communication Systems (PACS). The Radiology department provides diagnostic and interventional radiology for inpatients, outpatients and general practitioner referrals. Various healthcare services such as Computed Radiography (CR), Computed Tomography (CT), X-ray, and Interventional Radiology produce a huge amount of information regarding patient's healthcare delivery and clinical process. Both relevant employees of the company and clinicians in the hospital are selected for the interview.

To select appropriate case, a method developed by Seawright and Gerring (2008) is adopted. Following the method, firstly the selection method is qualitative research approach. Secondly, the goal of the feasibility study is to support the feasibility of the proposed SIEF by conducting interviews. Thirdly, the size of the case is medium enterprise which has approximately 200 employees working on various projects. The project where this case study conducts involves 28 staff, and from the hospital side, 15 clinicians are involved.

To select appropriate interviewees, several criteria are set up for the screening process. Firstly, by working experiences: should have more than 3-year experiences relating to software and systems development for employee; and should have more than 3year experiences directly using the above information systems for clinicians. Secondly, by technical relevance: should have been directly involved in the development, other supporting roles are not accepted for employee; because the clinician is the user, this criterion does not apply to them.

Following the two criteria, 31 semi-structured interviews (summarised in Table 2) were conducted with relevant stakeholders. The interviews lasted around 40 minutes and were on a one-to-one basis. The interviews were tape-recorded and later transcribed and rendered anonymously. The questions asked are derived from the SIEF which is 
presented in the next Chapter. The results of the interviews are summarised into categories presented in the following sections.

Table 2. Summary of interviews

\begin{tabular}{lllllll}
\hline Sectors & Sample & \multicolumn{2}{l}{ Years of experience } & & & \\
& & $\mathbf{3 - 5}$ & $\mathbf{6 - 1 0}$ & $\mathbf{1 1 - 1 5}$ & $\mathbf{1 6 - 2 0}$ & $\mathbf{2 0 +}$ \\
\hline Industry & 22 & 7 & 11 & 2 & 1 & 1 \\
Hospitals & 9 & 3 & 2 & 1 & 1 & 2 \\
Total & 31 & 10 & 13 & 3 & 2 & 3 \\
\hline
\end{tabular}

22 participants from industry have been interviewed: 6 of them are junior-manager level, 10 of them are senior-manager level e.g. senior system architect, project manager; and 6 of them are executive level e.g. CEO, CTO, director of software design, and director of service delivery.

9 participants from hospitals have been interviewed: 4 of them are physicians, 3 of them are radiology technicians, 1 IT manager with 11 years' experiences, and 1 medical administration manager.

The open interview basically asked what concerns and barriers should not be ignored when assessing interoperability from the three layers: the technical, the formal, and the informal. As the purpose of the interview is to investigate the feasibility of interoperability assessment, thus the questions asked aim to gather wide opinions from those participants, and more specific data analysis techniques such as content analysis are not applied. The key results from the interview are summarised in following paragraphs.

To enable collaboration between business processes, a shared intended purpose plays a key role that supports perceiving of personal beliefs and organisational ground rules, whereas an un-shared purpose may be considerable conflicts between the organisational level and personal level. Issues like restriction to staff behaviour, information collaboration (information channels alignment), and privacy and security concerns are raised attentions. Taking one example from one of the interviewed hospital, the informal level is concerned with the understanding of the healthcare, regulatory, legislative and healthcare environment in which information systems need to be deployed to support healthcare delivery. It requires agreement on key organisational concepts such as policies, processes and roles; it also captures relevant patterns such as compliance, governance, legislative and change management. Table 3 summarises the concerns and barriers at informal layer from the interview.

Table 3. Concerns and barriers at informal layer summarised from interview results

\begin{tabular}{ll}
\hline Culture issue & Tacit knowledge has not been explicitly stated and shared \\
Ethical issue & $\begin{array}{l}\text { Appropriateness of taking actions on healthcare service deliv- } \\
\text { ery }\end{array}$ \\
$\begin{array}{l}\text { Behavioural fac- } \\
\text { tor }\end{array}$ & Willingness to be open and to share \\
\hline
\end{tabular}




\begin{tabular}{ll}
\hline Management style & $\begin{array}{l}\text { Leadership style influencing the degree of willingness of col- } \\
\text { laboration }\end{array}$ \\
$\begin{array}{l}\text { Policy and proce- } \\
\text { dure }\end{array}$ & $\begin{array}{l}\text { Internal control process, work flow, staff relationships, com- } \\
\text { munication patterns, cut-across political boundaries, etc. }\end{array}$ \\
$\begin{array}{l}\text { Restriction to staff } \\
\text { behaviour }\end{array}$ & $\begin{array}{l}\text { Staff's fear on integrated working process as restriction that } \\
\text { might control their behaviour } \\
\begin{array}{l}\text { Privacy and secu- } \\
\text { rity }\end{array}\end{array}$ \\
\hline
\end{tabular}

At Formal layer, the concerns and barriers are collected from the interview and observation are summarised in Table 4. To assess interoperability, we should not only be concerned with information exchanged between technical systems, but also the knowledge of the context that the information exists within each system or process. As quoted from one IT project managers: “...It is important to articulate the requirement for context awareness that process representation begins. The context of the target system should also be made available to the origin system. Key questions such as what process will first operate on the information at the target system once it receives it, and what state of preceded processes are should be concerned..." By understanding this context, the system engineer and integration designer can ensure pragmatic interoperability is addressed for the needs of process integration. To define the context, one manager of the logistics department said that "Assume that the context is about internal workings of the process, in other words, the initialization state, the end state, the nature of data transformations, and details about the timing of the process are all considered, so that the receiving process can make better use of information it receives. This information is in context, but it also shows the dynamic nature of that context to the receiving system, because it now has specific information about the dynamic context within the originating system."

Table 4. Concerns and barriers at formal layer summarised from interview results

Organisation structure

Harmonized strategy

Performance constraints

Cost constraints

Data source interoperability

\section{Context awareness}

Varieties of purchased systems
Centralised, decentralised, hierarchical, matrix, networked, etc.

Aligned operations to be applicable on the strategic level

Fewer investment but more effective collaboration Unexpected budget

Multiple data sources used for supporting process

Knowledge of context of both collaborative parties/processes

Purchased systems from various venders with low capability 
For example, context is seen as a demand for more information between the Model Manufacturing Demand Service and the Rental Fulfilment Service, so that a specific understanding of the models requested has a deeper meaning. This could be a specific based on the timing of the data, the initialization state of the Rental Fulfilment Service, and the data transformations. This gives a more dynamic picture of the context for the information being produced by one process for another, and allows for a deeper understanding of the meaning of that context.

The purpose at technical level is to make exchanged data available for supporting the processes at upper level. For example, in healthcare environment, it is concerned with the understanding of technical functionality for supporting information systems; from a project management perspective, the manager needs to ensure both data and service integration have been successfully implemented beforehand. It requires agreement on a core set of technical concepts, such as technical components and devices, the interactions between components, interface and technical services; it also captures relevant patterns such as technical architecture styles and styles of component interactions. However, the study at this level is not the focus of the interoperability evaluation in this thesis, although this layer is vital to support the understanding the concerns of pragmatic interoperability. Therefore, during the interview, only few concerns regarding technical level are summarised below.

Table 5. Concerns and barriers at technical layer summarised from interview results

\begin{tabular}{|c|c|}
\hline $\begin{array}{l}\text { Semantic hetero- } \\
\text { geneity }\end{array}$ & $\begin{array}{l}\text { Refers to the variation of semantic meaning in information re- } \\
\text { sources which will lead to the semantic conflicts and complica- } \\
\text { tion for data integration }\end{array}$ \\
\hline $\begin{array}{l}\text { Ontology struc- } \\
\text { ture }\end{array}$ & Approaches that employ ontologies for information systems \\
\hline $\begin{array}{l}\text { Business seman- } \\
\text { tics }\end{array}$ & Defining ontology and semantic conversion \\
\hline $\begin{array}{l}\text { Ambiguous ter- } \\
\text { minology }\end{array}$ & Differences in the use of terms across departments \\
\hline $\begin{array}{l}\text { Implementation } \\
\text { of data integration }\end{array}$ & $\begin{array}{l}\text { Defining source and target data format; data transformation and } \\
\text { mapping; deploy on execution infrastructure }\end{array}$ \\
\hline $\begin{array}{l}\text { Implementation } \\
\text { of service integra- } \\
\text { tion }\end{array}$ & Services for connecting processes and message exchange \\
\hline
\end{tabular}

\section{Semiotic Interoperability Evaluation Framework}

Based on the findings from the feasibility study, key barriers are identified while considering the interoperability assessment. The empirical investigation supports the SIEF to derive its associated metrics. Besides, based on the previous works from Li (2010), Liu et al. (2014), Meyers et al. (2005), and other widely used interoperability evaluation 
frameworks, the assessment metrics are developed accordingly. Fig 2 presents the SIEF, and there are no explicit borderlines among the technical metrics, formal metrics, and informal metrics.

\begin{tabular}{|c|c|c|}
\hline Technical metric & $\begin{array}{c}\text { Formal metric } \\
\text { (Performance measure) }\end{array}$ & $\begin{array}{c}\text { Informal metric } \\
\text { (Indicator) }\end{array}$ \\
\hline \multirow{2}{*}{$\begin{array}{c}\text { Modelling business } \\
\text { document }\end{array}$} & Business strategy & \multirow{4}{*}{ Tradition and culture } \\
\hline & Clarity in strategic goals & \\
\hline High-level model & $\begin{array}{l}\text { Formal commitment to prevent } \\
\text { termination or premature collaboration }\end{array}$ & \\
\hline Components model & Backup strategic plan & \\
\hline $\begin{array}{l}\text { Implementation of data } \\
\text { integration }\end{array}$ & $\begin{array}{l}\text { Management of External } \\
\text { relationships }\end{array}$ & Management style \\
\hline $\begin{array}{l}\text { Source and target data } \\
\text { format definition }\end{array}$ & $\begin{array}{l}\text { Partner selection } \\
\text { Partner assessment } \\
\text { Operation contracts }\end{array}$ & Religions \\
\hline $\begin{array}{l}\text { Data mapping and } \\
\text { transformation }\end{array}$ & $\begin{array}{l}\text { Conflict resolution } \\
\text { Communication }\end{array}$ & $\begin{array}{l}\text { Appropriateness of } \\
\text { taking actions }\end{array}$ \\
\hline $\begin{array}{l}\text { Implementation of } \\
\text { service integration }\end{array}$ & $\begin{array}{c}\text { Collaborative business processes } \\
\text { management }\end{array}$ & \multirow[t]{2}{*}{ Employee's motivation } \\
\hline Deployment on execution & Clarity in responsibility & \\
\hline $\begin{array}{c}\text { infrastructure } \\
\text { Services for connecting } \\
\text { processes }\end{array}$ & $\begin{array}{l}\text { Business process modelling } \\
\text { Clarity in business process } \\
\text { Process visibility }\end{array}$ & Employee's honesty \\
\hline Services for message & IPR management & \multirow[t]{2}{*}{ Resistance to change } \\
\hline exchange & IPR protection & \\
\hline Business semantics & $\begin{array}{l}\text { Potential IPR } \\
\text { IPR Conflicts }\end{array}$ & \multirow{2}{*}{$\begin{array}{l}\text { Fear of behaviour } \\
\text { control by others }\end{array}$} \\
\hline $\begin{array}{l}\text { Ontology definition } \\
\text { Semantic conversion }\end{array}$ & $\begin{array}{c}\text { Organisational structures } \\
\text { Role mapping }\end{array}$ & \\
\hline
\end{tabular}

Fig. 2. Semiotic Interoperability Evaluation Framework (SIEF)

This paper tends to not view the interoperability assessment separately by levels, but to think it as a whole. The three levels in the SIEF are all concerned with the pragmatic and social levels in the semiotic framework. If there must be borderline in between, then the group of technical and formal metrics, and informal metrics could match the pragmatic and social levels respectively with overlapping. The relation between the metrics in the SIEF and the levels in the semiotic framework is that the pragmatic levels and social levels comprise but not limited to those levels.

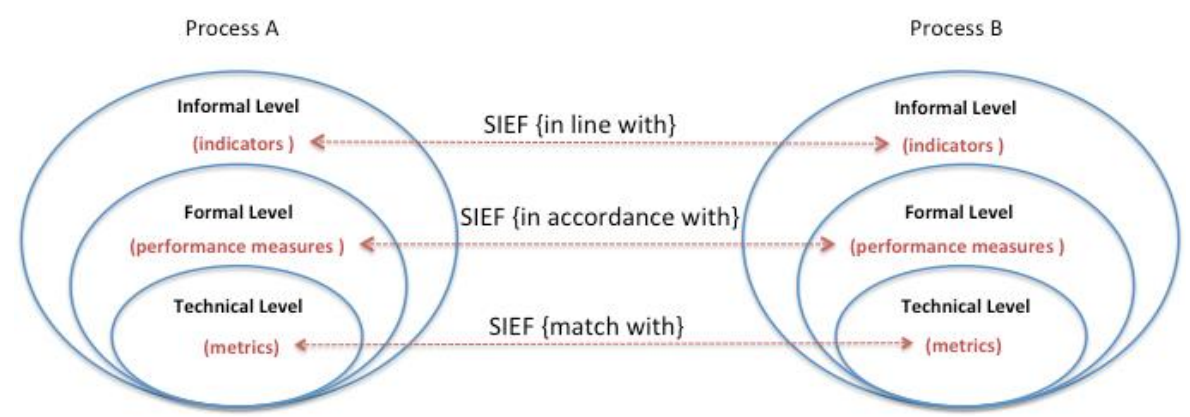

Fig. 3. Interoperability between business process A and B 
Therefore, the interoperability between the two business processes is the combination of the interoperability at the three levels, which can be presented as the Equation (1):

$$
x+y=z
$$

$\mathrm{I}\left(\mathrm{P}_{\mathrm{a}}, \mathrm{P}_{\mathrm{b}}\right)$ : Interoperability between two processes $\mathrm{A}$ and $\mathrm{B}$; $\mathrm{I}_{\mathrm{Te}}\left(\mathrm{P}_{\mathrm{a}}, \mathrm{P}_{\mathrm{b}}\right)$ : Interoperability at technical level; $\mathrm{I}_{\mathrm{Fo}}\left(\mathrm{P}_{\mathrm{a}}, \mathrm{P}_{\mathrm{b}}\right)$ : Interoperability at formal level; $\mathrm{I}_{\mathrm{In}}\left(\mathrm{P}_{\mathrm{a}}, \mathrm{P}_{\mathrm{b}}\right)$ : Interoperability at informal level.

Figure 3 illustrates how the interoperability evaluation is conveyed between two business processes. In the informal level, the metric is also named indicator, which means the indicators of process A such as the management style, religions, appropriateness of taking actions, employee's motivation, employee's honesty, should be in line with the indicators of process B. in the formal level, the metric is also named performance measure, which means the measures of process A such as clarity in business strategy, backup strategic plan, management of External relationships, clarity in responsibility, should be in accordance with the performance measures of process B. In the technical level, the metrics of process A such as design of services, model of business document, and implementation of data/service integration, should match with the metrics of process $\mathrm{B}$.

\section{$5 \quad$ Conclusion and Future Work}

Assessing interoperability is still challenging because those metrics cannot be easily quantified for more specific measurement. As discussed previously, on one hand, the metrics are partly derived from results of the case study, which reflect key concerns and barriers of interoperability; on the other hand, there are also metrics derived from the existing works, which have been explained in the previous section. For each metric/concern/barrier, we have investigated corresponding solutions/methods/tools, which will be used as criteria to evaluate that whether the concern or the barrier has been addressed or not. In this case, to measure each metric, all relevant methods, solutions, and tools will be developed in future work.

\section{References}

1. Barbarito, F., Pinciroli, F., Mason, J., Marceglia, S., Mazzola, L., \& Bonacina, S. (2012). Implementing standards for the interoperability among healthcare providers in the public regionalized Healthcare Information System of the Lombardy Region. Journal of Biomedical Informatics, 45(4), 736-745. https://doi.org/10.1016/j.jbi.2012.01.006

2. Boonstra, A., Broekhuis, M., Offenbeek, M. Van, \& Wortmann, H. (2011). Strategic alternatives in telecare design: Developing a value-configuration-based alignment framework. Journal of Strategic Information Systems, 20(2), 198-214. https://doi.org/10.1016/j.jsis.2010.12.001 
3. Chen, D., Doumeingts, G., \& Vernadat, F. (2008). Architectures for enterprise integration and interoperability: Past, present and future. Computers in Industry, 59(7), 647-659. https://doi.org/10.1016/j.compind.2007.12.016

4. Clabby, J. (2003). Web Services Explained: Solutions and Applications for the Real World. Prentice Hall PTR, Upper Saddle River (NJ).

5. EN/ISO I9439. (2003). Enterprise integration-Framework for enterprise modelling. Work Report.

6. Gregory, S., Dixon, A., \& Ham, C. (2012). Health policy under the coalition government A mid-term assessment Editors. The King's Fund.

7. Kaye, D. (2003). Loosely coupled: the missing pieces of Web services. RDS Press. RDS Strategies LLC.

8. Li, W. (2010). The Architecture and Implementation of Digital Hospital - Information System Integration for Seamless Business Process. Ph.D Thesis. Univerity of Reading: Ph.D Thesis.

9. Liu, K. (2000). Semiotics in Information Systems Engineering. Cambridge: Cambridge University Press. https://doi.org/10.1017/CBO9780511543364

10. Liu, S., Li, W., \& Liu, K. (2014). Pragmatic Oriented Data Interoperability for Smart Healthcare Information Systems. In The 14th IEEE/ACM International Symposium on Cluster, Cloud and Grid Computing. Chicago, USA.

11. Panian, Z. (2006). Why enterprise system integration is inevitable? WSEAS Transactions on Business and Economics, 2006, 590-595.

12. Saag, K. G., Mohr, P. E., Esmail, L., Mudano, A. S., Wright, N., Beukelman, T., ... Tunis, S. R. (2012). Improving the efficiency and effectiveness of pragmatic clinical trials in older adults in the United States. Contemporary Clinical Trials, 33(6), 1211-1216. https://doi.org/10.1016/j.cct.2012.07.002

13. Stamper, R. (1973). Information in business and administrative systems. London: Batsford. Retrieved from http://www.getcited.org/pub/101449585

14. Zutshi, A., Grilo, A., \& Jardim-Goncalves, R. (2012). The business interoperability quotient measurement model. Computers in Industry, 63(5), 389-404. https://doi.org/10.1016/j.compind.2012.01.002 